\title{
DNA methylation dynamics at imprinted genes during bovine pre-implantation embryo development
}

\author{
Alan M O'Doherty ${ }^{1,2}$, David A Magee ${ }^{3}$, Lynee C O'Shea ${ }^{1}$, Niamh Forde ${ }^{1}$, Marijke E Beltman ${ }^{1}$, Solomon Mamo ${ }^{1}$ \\ and Trudee Fair ${ }^{1 *}$
}

\begin{abstract}
Background: In mammals, maternal differentially methylated regions (DMRs) acquire DNA methylation during the postnatal growth stage of oogenesis, with paternal DMRs acquiring DNA methylation in the perinatal prospermatagonia. Following fusion of the male and female gametes, it is widely accepted that murine DNA methylation marks at the DMRs of imprinted genes are stable through embryogenesis and early development, until they are reprogrammed in primordial germ cells. However, the DNA methylation dynamics at DMRs of bovine imprinted genes during early stages of development remains largely unknown. The objective of this investigation was to analyse the methylation dynamics at imprinted gene DMRs during bovine embryo development, from blastocyst stage until implantation.

Results: To this end, pyrosequencing technology was used to quantify DNA methylation at DMR-associated CpG dinucleotides of six imprinted bovine genes (SNRPN, MEST, IGF2R, PLAGL1, PEG10 and H19) using bisulfite-modified genomic DNA isolated from individual blastocysts (Day 7); ovoid embryos (Day 14); filamentous embryos (Day 17) and implanting conceptuses (Day 25). For all genes, the degree of DNA methylation was most variable in Day 7 blastocysts compared to later developmental stages $(P<0.05)$. Furthermore, mining of RNA-seq transcriptomic data and western blot analysis revealed a specific window of expression of DNA methylation machinery genes (including DNMT3A, DNMT3B, TRIM28/KAP1 and DNMT1) and proteins (DNMT3A, DNMT3A2 and DNMT3B) by bovine embryos coincident with imprint stabilization.
\end{abstract}

Conclusion: The findings of this study suggest that the DNA methylation status of bovine DMRs might be variable during the early stages of embryonic development, possibly requiring an active period of imprint stabilization.

Keywords: Embryo, DNA methylation, Genomic imprinting, Bovine, Preimplantation embryos, Epigenetic reprogramming, DNA methyltransferases

\section{Background}

The epigenetic process of genomic imprinting enables parent-of-origin expression of a cohort of mammalian genes [1]. Imprinted genes have been shown to play a pivotal role in embryonic growth, development, placental function and postnatal behaviour and metabolism [2-5]. The distinctive monoallelic expression of imprinted genes is facilitated through asymmetrical epigenetic marks on either the maternal or paternal allele. Generally, imprinted

\footnotetext{
* Correspondence: trudee.fair@ucd.ie

${ }^{1}$ School of Agriculture and Food Science, University College Dublin, Belfield, Dublin, Ireland

Full list of author information is available at the end of the article
}

genes are arranged in clusters containing differentially marked, CpG rich domains, known as imprint control regions (ICRs) and/or differentially methylated regions (DMRs); the most extensively studied of these marks is DNA methylation [6]. Mammalian DNA methylation patterns required for genomic imprinting are subject to periods of dynamic reprogramming during development and are established at different developmental time points, depending on which germline they are transmitted through. Paternal DMRs acquire their methylation marks in the prospermatagonia, with completion occurring prior to birth $[7,8]$; while DNA methylation marks

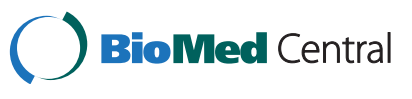


at maternal DMRs are established postnatally in the growing oocyte [9-11].

Following fertilization, a global cascade of DNA demethylation is evident in the preimplantation embryos of a number of mammalian species including mouse, rat and cattle $[12,13]$. This demethylation event occurs actively on the paternal genome in one cell embryos $[14,15]$ and passively on the maternal genome following each cell division from the two cell stage until blastocyst in mouse [16] and up to the 8-cell stage in bovine [12]. Interestingly, studies in mice have shown that the DNA methylation landscape at the DMR of the imprinted H19 gene is resistant to these pan-genomic demethylation events $[17,18]$. Although information is available in mice [19-21] and there is some information on non-imprinted and imprinted genes in bovine embryos [22,23], the fate of maternally methylated imprinted gene DMRs remains largely undetermined during the early stages of bovine embryogenesis, especially so between blastocyst stage and implantation. Indeed, it has been suggested that murine DNA methylation imprints may be dynamic in the early embryo [24]. However, this study demonstrated that regions around maternally methylated germ line DMRs may undergo some changes, leaving a core DMR methylated. Extensive work has been carried out to elucidate which genes are involved with establishing and maintaining DNA methylation marks, and it is now widely accepted that the DNA methyltransferase genes (Dnmt3a, Dnmt3b and Dnmt3L) are responsible for establishing DNA methylation imprints in the male and female germline [25]; with Dnmt1 and Uhrf1 being primarily implicated with maintenance of methylation marks following DNA replication [26-28]. Gene targeting studies in mice have demonstrated that the methyltransferases Dnmt3a, Dnmt3b and Dnmt1 are indispensable for embryonic survival $[29,30]$. With regards to Dnmt3L, transgenic mice carrying homozygous null mutations are viable [31]; however, Dnmt $3 \mathrm{~L}^{-/-}$male mice are infertile due to reactivation of long interspersed elements (LINE-1) and retrotransposons as well as meiotic catastrophe [32,33], while females fail to deliver viable pups as a result of hypomethylation at imprinted loci [34]. More recently, expression of Trim28/Kap1 and Zfp57 have been associated with the regulation of epigenetic stability in mouse oocytes and embryos $[35,36]$. In addition to establishing and maintaining DNA methylation marks, evidence suggests that the Ten-eleven translocation methylcytosine dioxygenase (TET) family members play a central role in active demethylation [37].

In cattle, developmental epigenetic research has primarily focused on cloned bovine embryos, due to the low survival rates of embryos produced by somatic cell nuclear transfer (SCNT). A high degree of SCNT embryonic loss occurs during the preimplantation period [38] with further loss and morphological anomalies (enlarged placentomes, enlarged umbilical cords and large offspring syndrome) being observed in embryos that successfully implant and progress through gestation [39-41]. It has been suggested that this low survivability ( $5-8 \%$ development to term) [42], may be due to erroneous epigenetic reprogramming $[43,44]$, such as aberrant DNA methylation patterns observed at the imprinted SNRPN locus in Day 17 SCNT embryos [45]. Monoallelic expression and DNA methylation patterns of imprinted genes associated with the human epigenetic disorder, Beckwith-Wiedemann syndrome, have also been shown to be conserved in bovine Day 65 concepti [46]. The role of DNA methylation programming has also been highlighted in studies involving DNMT1 siRNA-based knockdown experiments during in vitro development of bovine SCNT embryos. These investigations suggest that a significant increase in development to blastocyst was due to enhanced reprogramming efficiency elicited by DNA demethylation in DNMT1 knockdown embryos [47]. In a recent study using fluorescent labelling techniques, Dobbs and colleagues revealed global methylation patterns in pre-implantation bovine embryos [48]. Results from this study showed that methylation patterns significantly differ between male and female embryos and that, in the blastocyst, the inner cell (ICM) mass is less methylated when compared to the trophectoderm (TE), confirming previous findings by $\mathrm{Hou}$ et al. [49]. However, in contrast to the investigations carried out on cloned embryos, non-manipulated in vivo derived embryos have received limited attention, particularly prior to Day 17.

In the current study, we investigated the DNA methylation profiles at DMRs of six bovine imprinted genes (SNRPN, MEST, IGF2R, PLAGL1, PEG10 and H19) in in vivo derived embryos at several stages of development, including blastocyst and peri-implanting conceptuses. In addition, the abundance of RNA transcripts, and proteins, known to be associated with the establishment and maintenance of DNA methylation imprints were determined in embryos at parallel stages of development.

\section{Methods}

\section{Ethical approval}

All experimental procedures involving animals were licensed by the Department of Health and Children, Ireland, in accordance with the Cruelty to Animals Act, 1897, and the European Community Directive 86/609/EC. All procedures were sanctioned by the University College Dublin, Ireland Animals Research Ethics Committee. All animals were processed in a commercial abattoir.

\section{Animal synchronization and embryo collection}

Collection of in vivo derived bovine embryos was performed using a previously described synchronization 
protocol [50,51]. Briefly, crossbred beef heifers (approximately 18-24 months old) were synchronized using an 8-Day CIDR treatment (Controlled Internal Drug Release device, $1.36 \mathrm{~g}$ progesterone; Pfizer Animal Health Worldwide) with administration of a prostaglandin PGF2 $\alpha$ analogue (Estrumate MSD Animal Health, containing 0.5 $\mathrm{mg}$ cloprostenol) injection one Day prior to removal of the CIDR. Animals were checked for estrus four times daily, from $36 \mathrm{~h}$ following PGF2 $\alpha$ injection. Animals that were in standing estrus between $36-60 \mathrm{~h}$ were inseminated using frozen thawed semen. Inseminated animals were slaughtered and embryos recovered from reproductive tracts on Days $7(n=10), 14(n=8), 17(n=10)$ and $25(n=8)$.

\section{DNA modification}

Isolation and bisulfite modification of DNA was carried out using the EZ methylation direct method (Zymo Research) according to manufacturer's guidelines. Firstly, proteinase $\mathrm{k}$ digestion was performed in a $20 \mu \mathrm{l}$ reaction volume, containing $1 \mu \mathrm{g} / \mu \mathrm{l}$ proteinase $\mathrm{K}$ and $1 \times \mathrm{M}$ digestion buffer, at $50^{\circ} \mathrm{C}$ overnight. Sample input for the digests were as follows; individual Day 7 or $2 \mu \mathrm{l}$ (from a total volume equal to $6 \mu \mathrm{l}$ ) of disaggregated Day 14, Day 17 embryonic disc and Day 25 embryo proper. For trophectoderm (Day 17) and extraembryonic (Day 25) samples a $2 \mathrm{ul}$ aliquot was used. Following this, $130 \mu \mathrm{l}$ of fresh CT conversion reagent (sodium bisulfite conversion solution) was added directly to the digests which were then incubated at $98^{\circ} \mathrm{C}$ for $8 \mathrm{~min}$ and $64^{\circ} \mathrm{C}$ for $8 \mathrm{~h}$. Bisulfite DNA clean-up was carried out by adding the CT conversion reactions to Zymo-Spin columns preloaded with $600 \mu \mathrm{l} \mathrm{M}$-binding buffer, centrifugation at $13,000 \mathrm{rpm}$, washing with $100 \mu \mathrm{l} \mathrm{M}$-wash buffer, desulphonation at room temperature for $25 \mathrm{~min}$ and a further two washes with $200 \mu \mathrm{l} \mathrm{M}$-wash buffer. Samples were eluted in $42 \mu \mathrm{l}$ elution buffer, warmed to $50^{\circ} \mathrm{C}$ to enhance recovery. Liver, kidney and heart samples were modified as in [11]. For experiments using limited starting amounts of DNA, the DNA was extracted using an AllPrep DNA/RNA Micro Kit (Qiagen) and quantified using a Qubit ${ }^{\circ}$ dsDNA high sensitivity assay kit and a Qubit $^{\circ}$ 2.0 Fluorometer (LifeTechnologies).

\section{Bisulfite PCR}

Bisulfite PCR reactions were carried out in $25 \mu \mathrm{l}$ reactions using primers outlined in (Additional file 1: Table S2) Each PCR reaction contained 1 X PCR buffer (minus $\mathrm{MgCl}_{2}$ ), $0.2 \mu \mathrm{m}$ forward and reverse primer, $2 \mathrm{mM}$ $\mathrm{MgCl}_{2}, 1.25 \mathrm{U}$ Platinum Taq DNA polymerase and $6 \mu \mathrm{l}$ bisulfite DNA template. Amplification conditions were as follows: initial denaturation; $95^{\circ} \mathrm{C} 3 \mathrm{~min}$, followed by 40 cycles of $95^{\circ} \mathrm{C}$ denaturation for $30 \mathrm{sec}$, variable ${ }^{\circ} \mathrm{C}$ annealing for $30 \mathrm{sec}$ and $72^{\circ} \mathrm{C}$ elongation for $30 \mathrm{sec}$, with a final elongation step at $72^{\circ} \mathrm{C}$ for $5 \mathrm{~min}$. All reagents were supplied by Invitrogen Life Technologies ${ }^{\mathrm{Th}}$.

\section{Pyrosequencing}

Pyrosequencing assays for DMRs at maternally imprinted genes were verified previously [11]. The $H 19$ assay was designed according to previously identified DMR [52] and verified in Additional file 2: Figure S1. Biotin labeled bisulfite PCR products, verified by agarose gel electrophoresis, were made up to $80 \mu \mathrm{l}$ reaction volumes containing $2 \mu \mathrm{l}$ streptavidin-coated Sepharose beads (GE Healthcare), $20 \mu \mathrm{l}$ nuclease free $\mathrm{H}_{2} \mathrm{O}$ and $40 \mathrm{ul}$ binding buffer (Qiagen). Mixtures were agitated, to enable binding of biotin labeled strands to beads, by shaking at room temperature for 5 min. Template-bead complexes were immobilized to individual prongs on a Pyromark Q24 vacuum manifold (Qiagen) and subjected to a $10 \mathrm{sec}$ ethanol wash (70\% ethanol, Sigma); 15 sec denaturation step (PyroMark denaturation solution) and final $20 \mathrm{sec}$ wash step in $1 \mathrm{X}$ PyroMark wash buffer. The vacuum manifold was turned off and the bound template-bead complexes released into $25 \mu \mathrm{l}$ primer mixes containing $0.3 \mu \mathrm{M}$ sequencing primer and PyroMark annealing buffer. Internal bisulfite controls were included in each pyrosequencing assay performed. Only sequences that passed the internal control $(>95 \%$ bisulfite conversion) were included in the analysis.

\section{Statistical analysis of methylation data}

For this study, DMR methylation value was treated as a continuous variable. Pairwise group comparison of the variance in methylation for each gene was analysed using Levene's homogeneity of variance test [53], which assumes data are not normally distributed. A $P$-value threshold of $\leq 0.05$ was chosen to identify significant differences in the variance between groups. All analyses were performed using the Minitab version 16 software package (Minitab Ltd, Coventry, UK).

\section{Gene and protein expression analysis}

The TPM values for each gene of interest were retrieved from a bovine embryo RNA-seq dataset [54]. The TPM values were $\log$ transformed and analyzed by the statistical package SAS (SAS Institute, Cary, NC). Analysis was performed using general linear model procedure (PROC GLM) with Day as the main effect. Effect of Day on embryo/conceptus gene expression were separated by Tukey's test and a $P$ value of $<0.05$ was considered significant. Gene expression data are presented as the mean $\mathrm{TPM} \pm \mathrm{SE}$. DNA methyltransferase protein analysis was carried out using whole Day 7 embryos or small fragments of Day 13 and 25 embryos essentially as described previously [11]. 


\section{Experimental model}

The methylation profiles of six bovine genes (Figure 1A) known to undergo genomic imprinting were analysed $[11,52]$ (see also http://www.geneimprint.com/site/genesby-species.Bos+taurus). These included the maternally imprinted small nuclear ribonucleoprotein polypeptide $\mathrm{N}$ gene $(S N R P N)$; mesoderm specific transcript homolog [mouse] gene (MEST); insulin-like growth factor 2 receptor gene (IGF2R); pleiomorphic adenoma gene-like 1 gene (PLAGL1); paternally expressed 10 gene (PEG10) and the paternally imprinted maternally expressed transcript gene (H19). The number of DMR-associated CpG dinucleotides analysed for each gene were as follows: SNRPN $(n=12$, number of CpGs in island $=67)$; MEST $(n=15$, number of
CpGs in island = 119); IGF2R $(n=12$, number of CpGs in island =108); PLAGL1 $(n=11$, number of CpGs in island $=84)$; PEG10 ( $n=8$, number of CpGs in island = 78 ) and $H 19$ ( $n=8$, number of CpGs in island $=45)$. The DNA methylation status of each individual CpG was determined by pyrosequencing, with the average methylation status of each gene (herein referred to as methylation value) calculated for single in vivo embryos at different stages of development (Additional file 3: Table S1).

Investigations performed using mice models [16] have demonstrated that DNA methylation at imprinted loci is resistant to early embryonic DNA methylation reprogramming events. Therefore, we hypothesised that a
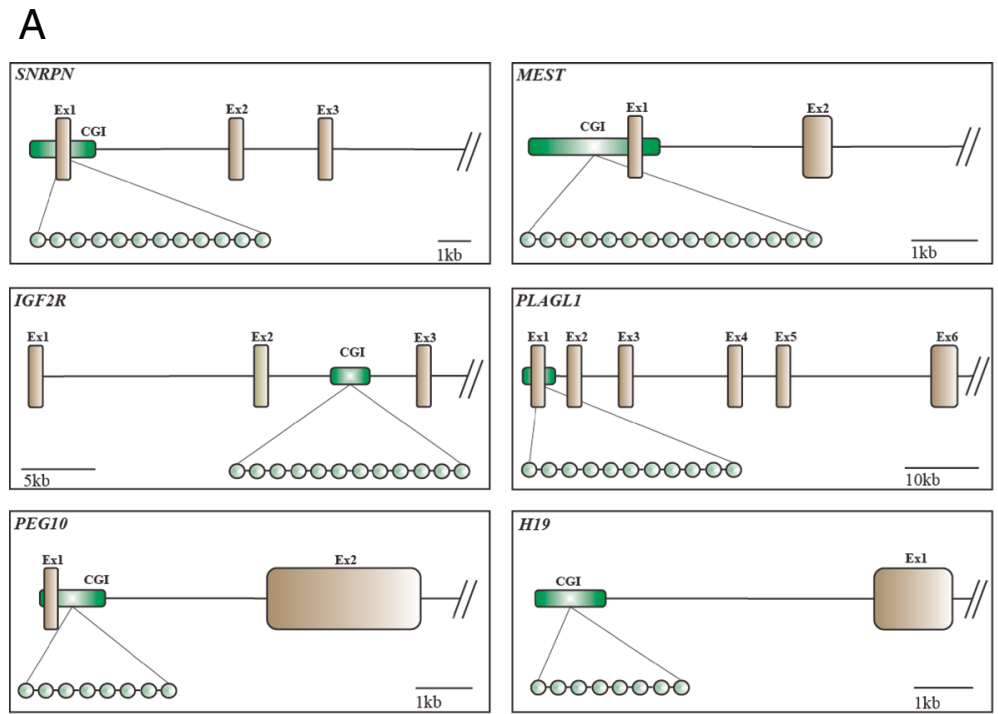

B
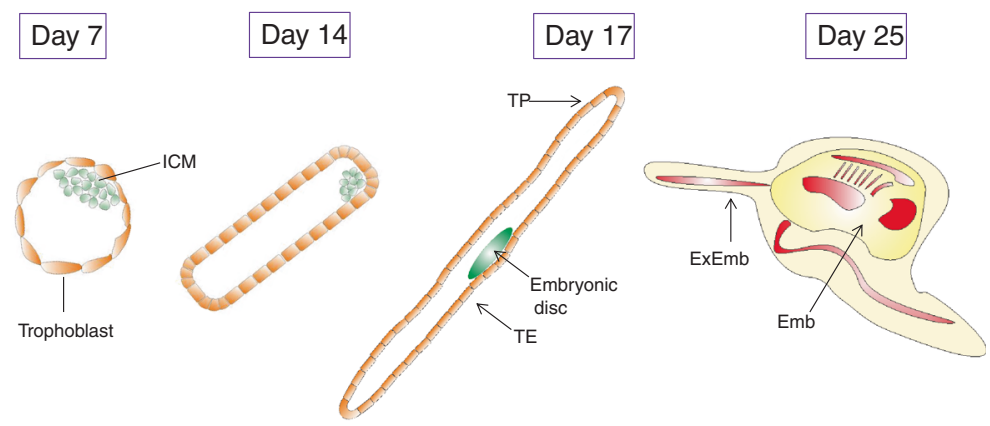

Blastocyst Hatched Ovoid

Filamentous Embryo

Implanting Conceptus

Figure 1 Schematic representation of samples and imprinted genes analysed. (A) Location of imprinted gene CpG islands (green box labelled GGI) and CpG dinucleotides covered by pyrosequencing analysis. Genes investigated were (clockwise from top left); SNRPN, MEST, PLAGL1, H19, PEG10 and IGF2R. (B) in vivo embryos from non-stimulated, artificially inseminated heifers were isolated 7, 14, 17 and 25 Days post insemination and used for imprinted gene DNA methylation analysis. ICM = inner cell mass; TE = trophectoderm adjacent to embryonic disc; TP = trophectoderm peripheral; ExEmb $=$ extraembryonic and Emb = embryonic. 
similar mechanism exists at bovine imprinted loci. To test this hypothesis, the methylation patterns at a panel of DMRs, were assayed in embryos (Figure 1B) across the pre- and peri-implantation axis: blastocyst (Day 7), hatched ovoid embryo (Day 14), filamentous embryo (Day 17) and implanting conceptus (Day 25). In addition, the methylation status of these DMRs was analysed in trophectoderm (Day 17) and extra embryonic (Day 25) tissues. For the Day 17 embryos two sections of the trophectoderm, embryonic disc adjacent (TE) and trophectoderm peripheral (TP), were analysed, as differences in morphology [55] and function [56] have previously been identified between regions adjacent to the embryonic disc and the periphery of the trophectoderm. A minimum of 4 individual embryos were assayed at each time point.

\section{Results}

DMR methylation during pre-implantation embryogenesis Comparison across the different embryonic stages revealed that the greatest range in methylation values occurred at the Day 7 blastocyst stage (3-61\% [SNRPN]; 7-59\% [MEST]; 13-44\% [IGF2R]; 12-64\% [PLAGL1]; 759\% [PEG10] and 20-32\% [H19]), followed by the Day 14 hatched ovoid embryos (27-45\% [SNRPN]; 31-36\% [MEST]; 28-89\% [IGF2R]; 31-42\% [PLAGL1]; 22-37\% [PEG1O] and 21-31\% [H19]). Notably, the range of methylation values for all six genes analysed were narrower at the Day 17 and Day 25 embryonic stages (Figure 2).

Previous studies have shown that methylation at DMRs of imprinted genes is stably maintained throughout early embryonic development [57]. For each gene, we compared the variances in sample group methylation across the development time course. For this, each developmental stage was considered a sample group and all possible pairwise group combinations were compared using the Levene's test [53] for homogeneity of variance implemented in Minitab. This test does not assume an underlying normal distribution and is appropriate for comparing variances when sample sizes are small [58]. We hypothesised that stable inheritance and maintenance of methylation at imprinted loci across the preimplantation developmental stages analysed will result in non-significant differences in the variance of methylation values between sample groups (Levene's test $P \geq 0.05$ ). In contrast, fluctuations in methylation patterns across the pre-implantation developmental will result in significant differences in the variance of methylation values across sample groups (Levene's test $P \leq 0.05$ ).

Pairwise group comparisons revealed statistically significant differences $(P \leq 0.05)$ between the variance in methylation values between the Day 7 blastocysts relative to the later embryos for all genes. The variance of the PLAGL1 and PEG10 DMR methylation values at Day 7 was significantly greater to the variances observed for all three later developmental stages. In addition, the variance of the IGF2R methylation at Day 7 was significantly greater to that for the Day 17 and Day 25 embryos. Significantly greater variances were also observed for MEST (Day 7 versus Day 17), H19 and SNRPN (both Day 7 versus Day 25). Notably, pairwise comparison of the variance in methylation values of the six geneassociated DMRs at the later developmental stages (Day 14, Day 17 and Day 25) revealed no statistically significant differences $(P \geq 0.05)$. Furthermore, Day 17 and Day 25 embryonic methylation values were similar to those of adult somatic samples, from heart, liver and kidney (Figure 3). To address the possibility that the observed variability in the blastocyst stage embryos could be due to technical, not biological, variation pyrosequencing analysis was performed using limited starting amounts of DNA- representative of the DNA content from a single ( 1 ng DNA) or half ( 500 pg DNA) a bovine blastocyst. Variation of DMR methylation between the two groups was assessed using the Levene's test outlined above. No significant differences were observed between the two starting input amounts of DNA (Additional file 4: Figure S2A). However, further analysis of a subset of DMRs (SNRPN, PEG10 and H19) using D7 methylation values and methylation values using limited starting amounts of embryonic and somatic (heart and liver) DNA samples revealed some significant differences for SNRPN and PEG10 (Additional file 4: Figures S2B-C) and no differences for $H 19$ (Additional file 4: Figure S2D). When methylation was analysed using D17 methylation values (Additional file 3: Table S1) with low input (LI) D17 samples, with same cell equivalents of D7 samples, SNRPN and PEG10 showed no significant differences (Additional file 4: Figure S2B (i) \& S2C (i)). In a similar experiment using D25 samples SNRPN showed significant difference, while PEG10 did not (Additional file 4: Figure S2B (ii) \& S2C (ii)). Comparison of D7 methylation values (Additional file 3: Table S1) with LI somatic and LI embryonic methylation values demonstrated that D7 values were significantly different to LI somatic values and not to LI embryonic methylation values (Additional file 4: Figure S2B (iii) \& S2C (iii)).

\section{Trophectoderm DMR methylation}

As the elongating/filamentous embryo is comprised of embryonic disc and trophectoderm tissues, we analysed and compared the variance in methylation values for each gene-associated DMR for these tissues at the Day 17 developmental stage. Three sample types were included in this analysis-embryonic disc (ED), trophectoderm peripheral (TP) and trophectoderm adjacent to the embryonic disc (TE). Comparisons of variance in methylation 

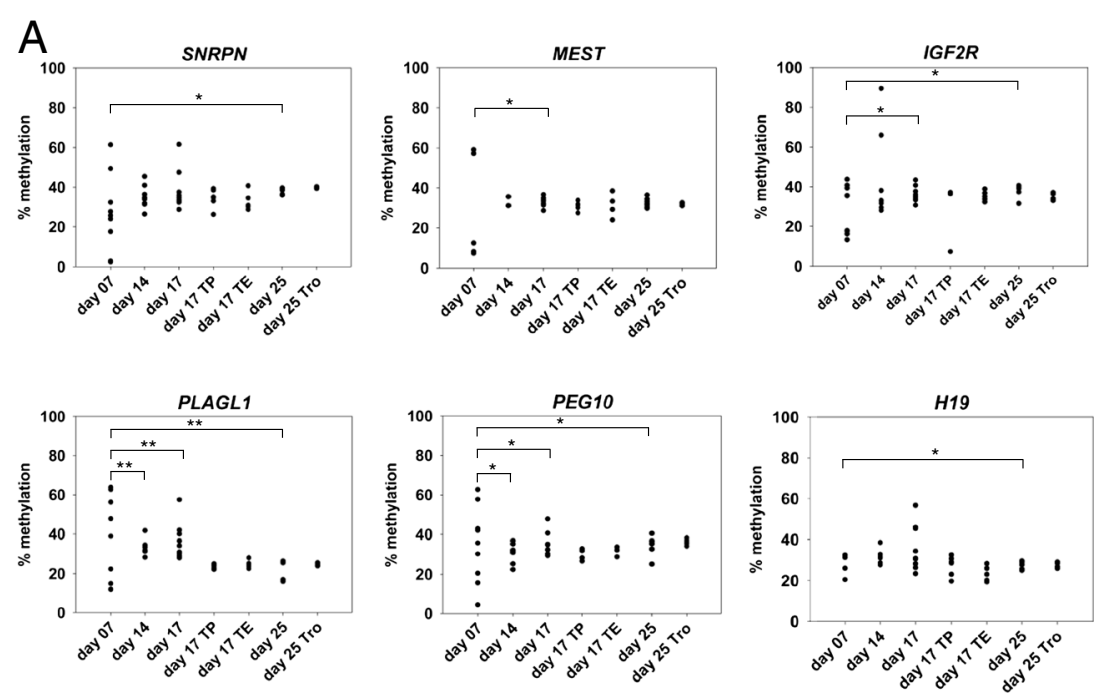

${ }^{*} P \leq 0.05,{ }^{* *} P \leq 0.01$

B

Standard deviation of embryo DMR methylation values

\begin{tabular}{lcccccc}
\hline Stage & SNRPN & MEST & IGF2R & PLAGL1 & PEG10 & H19 \\
\hline Blastocyst (d7) & 19.36 & 26.89 & 12.33 & 21.91 & 19.18 & 5.5 \\
Hatched Ovoid (d14) & 5.9 & 3.18 & 22.19 & 4.23 & 4.82 & 3.46 \\
Filamentous Embryonic Disc (d17) & 9.69 & 2.36 & 3.78 & 9.15 & 6.08 & 10.58 \\
Filamentous Trophectoderm (d17TE) & 4.69 & 2.33 & 14.75 & 1.15 & 2.74 & 4.89 \\
Filamentous Trophectoderm (d17TP) & 4.43 & 6.14 & 2.58 & 1.82 & 2.57 & 3.57 \\
Implanting Concepti (d25) & 1.67 & 2.35 & 3.13 & 5.07 & 5.24 & 1.83 \\
Implanting Concepti Ex Em (d25) & 0.45 & 0.65 & 1.88 & 0.69 & 1.57 & 1.32 \\
\hline
\end{tabular}

\section{Average Methylation Values}

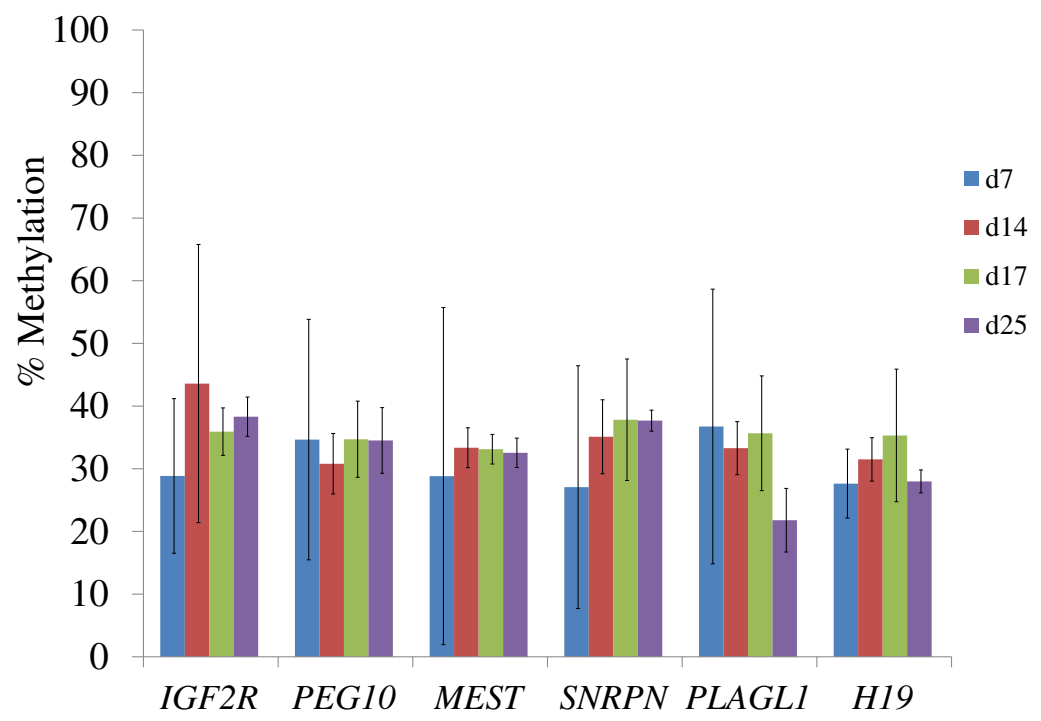

Figure 2 (See legend on next page.) 
(See figure on previous page.)

Figure 2 Pyrosequencing analysis of DNA methylation at six bovine imprinted differentially methylated regions during early embryogenesis. Bisulfite PCR and pyrosequencing was performed using genomic DNA isolated from embryos $(n=8-10)$ at four separate time points; blastocyst (Day 7), hatched ovoid embryos (Day 14), filamentous embryos (Day 17) and implanting conceptuses (Day 25). At Day 17, trophectoderm embryonic regions adjacent (TE) and peripheral to the embryonic disc (TP) were analysed. Trophectoderm samples at Day 25 were also included in the analysis. An overall trend of imprint stabilization can be observed for the six genes with increasing Days of embryonic development, post blastocyst. (A) Methylation values for SNRPN, MEST, IGF2R, PLAGL1, PEG10 and H19 at Day 7 had the most significant differences, when compared to Days 14, 17 or 25. (B) Top Panel; Standard deviations were calculated using individual methylation values ( $n=4$ - 9) for all genes in each group. Overall, standard deviations are greatest in group 1 (Day 7 blastocyst) with the smallest degree of variation occurring in the Day 25 implanting concepti (group 6) and Day 25 implanting concepti extra embryonic region. Bottom panel; Average methylation values, plotted with standard deviation values, for embryos isolated 7, 14, 17 and 25 Days post insemination (groups 1-3 and 6 from top panel).

values were performed for each gene between ED and TE, ED and TP, and TP and TE. With the exception of the comparison between the ED and TE tissues $(P=0.04)$ for $M E S T$, there were no significant differences in the variance methylation observed (Figure 2A). Similarly comparison of variance in methylation values was carried out using data from Day 25 trophectoderm and Day 25 embryo samples. With the exception of SNRPN $(P \leq 0.05)$ no significant differences were observed.

\section{Methylation machinery abundance during bovine embryogenesis}

Analysis of global transcriptomic data generated by RNA-seq profiling of Day- 7, 10, 13, 16 and 19 bovine embryos [54], revealed an overall effect of embryonic stage on the RNA transcript abundance (transcripts per million, TPM) of genes associated with the establishment and maintenance of DNA methylation imprints, specifically DNMT3A, DNMT3B, DNMT1, and TRIM28/KAP1 $(P<0.05$, Figure $4 \mathrm{~A})$. These genes showed a significant temporal decrease in transcript copy number from Day 13 to 16 and Day 13 to $19(P<0.05)$. The expression of both DNMT3A and DNMT3B was also significantly reduced in Day 16 and 19 embryos compared to Day 10 embryos $(P<0.05)$. While, there was a trend for a decline in ZFP57, TET1-1 and TET1-3 mRNA abundances over time, this decrease was not statistically different. Transcripts for TET and UHRF1 family members, although expressed across all stages, were not significantly different. DNMT3L expression was not detected above background levels (Additional file 5: Figure S4). In addition to analysis of RNA, we also performed western blot analysis to investigate the levels of the DNA methyltransferases; DNMT3A, DNMT3A2 and DNMT3B, 


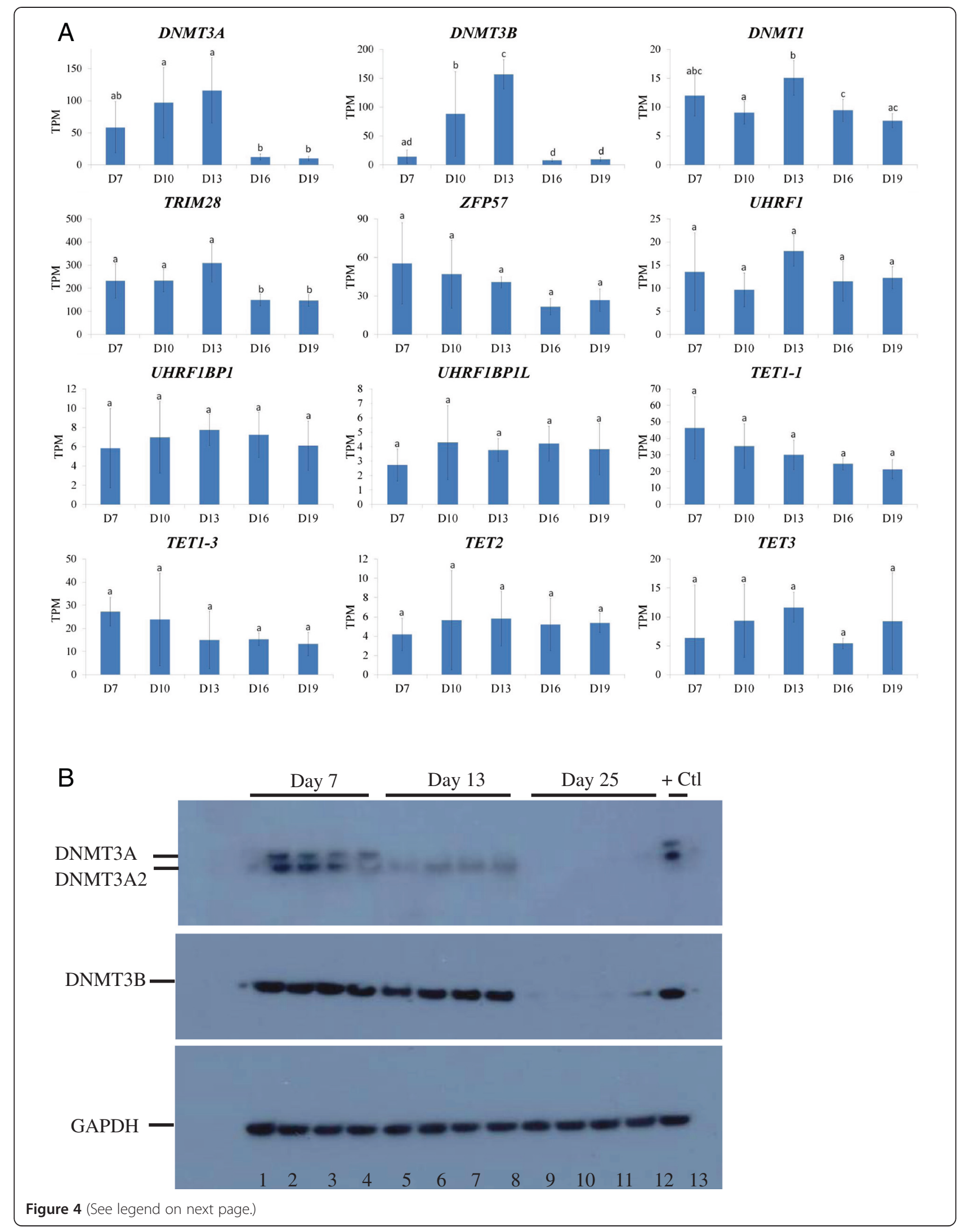


(See figure on previous page.)

Figure 4 Relative transcript abundance of DNMT3A, DNMT3B, DNMT1, TET family, UHRF1 family, TRIM28/KAP1 and ZFP57 over five developmental stages. (A) The TPM values for each gene of interest were retrieved from a bovine embryo RNA-seq dataset (43) generated from embryos $(n=5)$ at Day 7 (blastocyst), Day 10 (post hatching spherical embryo/conceptus), Day 13 (ovoid embryo/conceptus), Day 16 (filamentous embryo/coneptus) and Day 19 (filamentous embryo/conceptus; initiation of implantation). Bars with similar superscripts (abcd) are not significantly different $(P<0.05)$. A significant effect of embryonic stage on gene expression was observed for DNMT3A, DNMT3B, DNMT1 and TRIM28/KAP1. Although a trend of decreasing transcript abundance is apparent for TET1-1, TET1-3 and ZFP57, the decrease was not statistically significant. Transcripts per million (TPM). (B) Western blot analysis of the DNA methyltransferases; DNMT3A, DNMT3A2 and DNMT3B. All proteins were expressed in Day 7 blastocyst samples $(n=4)$ with DNMT3A and DNMT3B being expressed in all Day 13 embryos $(n=4)$. DNMT3 methyltransferase protein expression was not detectable in Day 25 conceptuses $(n=4)$. A positive control $(+\mathrm{Ctl})$ of total protein extracted from oocytes (shown previously to express the DNMT3 family members) was separated alongside the embryo samples.

using protein isolated from Day 7, 13 embryos and Day 25 conceptuses samples (Figure 4B). A similar pattern of expression was observed for these proteins that was also present in the RNA-seq analysis; demonstrating that both RNA and protein molecules are abundant during the period of DNA methylation imprint stabilisation.

\section{Discussion}

The current study details the methylation dynamics at a panel of differentially methylated imprinted gene loci, during pre- and peri-implantation bovine development. Results generated from this investigation have yielded novel information regarding the stability of DNA methylation imprints in this early developmental window. We provide evidence suggesting that DMRs may be subjected to a period of reprogramming in cattle, during the ontogeny from bovine blastocyst to hatched ovoid embryo/conceptus.

Current understanding of the fate of gametic DNA methylation marks at imprinted genes following fertilization has come from studies in mice $[17,18]$. These investigations, for example, have provided robust information regarding the paternally transmitted H19 DMR, demonstrating its stability during early embryonic development. Despite limited information regarding the early embryonic stability of maternally derived DNA methylation imprints, it is widely accepted that they follow a similar path to that of $H 19$ [16]. Here, we report for the first time a high level of variability in DNA methylation at the DMRs of imprinted genes in the bovine blastocyst, relative to levels detected at later stages of periimplantation embryo development. This is similar to previous results reported in human that showed, using pyrosequencing, variability of DNA methylation at DMRs of imprinted genes in single blastocysts [59]. These findings suggest that there possibly could be a wave of imprint stabilisation post blastocyst stage, following which, embryonic DMR methylation values become comparable to those observed in adult somatic tissues.

This observed variability in methylation could, however, be due to a number of possible reasons. Firstly, it is possible that the variation in DMR methylation observed in the bovine blastocyst may be due, in part, to technical issues, such as amplification bias of maternally- or paternally-derived genome copies involving small starting amounts of template material. To address this, pyrosequencing of each DMR was carried out using small amounts of bisulfite-modified heart and liver DNA, equivalent to the DNA content of single $(1 \mathrm{ng})$ and half a bovine blastocyst $(0.5 \mathrm{ng})$. While the effect of preferential amplification of maternal or paternal alleles cannot be fully excluded in the current study, there was a lack of statistical differences in DMR methylation between the two limited DNA starting concentrations demonstrating reliability of the assays using small amounts of gDNA. However, conflicting results were observed when using low starting amounts of D17 or D25 DNA. No differences were observed at the SNRPN, PEG10 or H19 DMRs when analysing D17 methylation values, but SNRPN was significantly different between D25 samples, suggesting the possibility of technical variation. Secondly, it is possible that there is an overrepresentation of DNA from the ICM or the TE in the Day 7 samples. Previous investigations have demonstrated differential global methylation patterns between the ICM and TE in bovine blastocysts. However, the results are unclear with reports indicating that the $\mathrm{TE}$ is more methylated $[48,49]$ and another showing higher methylation within the ICM [12]. Thirdly, the effect of hormonal treatment during animal synchronization on DMR methylation cannot be excluded as there is evidence to suggest that superovulation/ovarian stimulation regimes may interfere with methylation at the DMRs of imprinted genes in the murine blastocyst [60]. Fourthly, murine DMRs have been shown to be dynamic during murine preimplantation development in their ability to expand, contract or shift [24]. To identify whether the DMRs interrogated in this study were behaving in a similar manner, and thus contributing to the observed variation, methylation of individual CpGs for each gene was assessed on an embryo by embryo basis in the Day 7 group (Additional file 6: Figure S3). These analyses revealed that variation was consistent across all the CpGs of each DMR, indicating that the methylation variability was unlikely to be due to a small number losing or 
gaining methylation. Finally, previous studies investigating methylation at imprinted genes (H19 and Igf2) in embryonic germ cells, derived from either male or female primordial germ cells, identified that sex can contribute to differential methylation patterns at these loci [61-63]. Therefore, we cannot rule out that the sex of the embryos may be having an effect at DMRs at imprinted genes during the blastocyst stage.

Subsequent to the variability in methylation at D7, there was no difference in DMR methylation between trophectoderm regions and the embryo proper of implanting conceptuses, illustrating a pan-embryonic stability of DNA methylation at DMRs of imprinted gene. Considering the role of the trophectoderm in implantation and placenta formation [64], and given the role of genomic imprinting in placental function [65], these results are of particular interest. It has been previously proposed that normal function of the placenta may be impaired through alterations in the epigenetic landscape, such as those observed in cloned bovine placentas [66,67]. Here, we show that non-manipulated in vivo derived bovine embryos have a balanced methylation profile at DMRs of imprinted genes across the embryo proper and trophectoderm regions, suggesting that this may be the optimal imprinted gene methylation profile to support implantation and subsequent placental formation.

Targeted mining of bovine embryo global transcriptomic data [54] revealed a distinctive temporal RNA transcript profile for several key genes associated with establishing and maintaining imprints (DNMT3A, DNMT3B, DNMT1, TRIM28/KAP1 and ZFP57). High levels of mRNA expression were observed during the period of greatest imprint instability, followed by a significant decrease in transcript abundance at later stages of development, in tandem with DNA methylation imprint stabilization. This pattern of expression was also observed for DNMT3A, DNMT3A2 and DNMT3B, complementing the gene expression profiles. In mice, trim $28 /$ kap1 maternal knockouts present with severe phenotypic and epigenetic variability resulting in embryonic lethality [35], it has been proposed that an epigenetic complex formed by TRIM28/KAP1 and ZFP57 facilitate imprint maintenance/protection during the period of preimplantation reprogramming [68-70]. In addition, the de novo and maintenance DNA methyltransferases, DNMT3A/B and DNMT1, were shown to interact with ZFP57 through its co-factor TRIM28/KAP1 to maintain methylation imprints in embryonic stem cells $[36,69]$. Taking all things in to consideration, it is likely that TRIM28/KAP1 and ZFP57, along with the DNA methyltransferases $D N M T 3 A, D N M T 3 B$ and DNMT1 actively facilitate a window of DNA methylation reprogramming in bovine embryos post blastocyst development (Figure 5).



Figure 5 Overview of DMR methylation at imprinted genes and expression of associated transcripts in pre-implantation bovine embryos. Schematic representation of DNA methylation imprint dynamics following the blastocyst stage of bovine embryogenesis. Shaded grey area denotes the range of observed methylation values at imprinted loci during pre-implantation embryo development. Solid and dashed lines represents expression profiles of key genes associated with imprinted establishment and maintenance; blue dashed line DNMT3A and DNMT3B, solid orange line DNMT1 and TRIM28/KAP1 and solid orange-dashed orange line ZFP57, UHRF1 family and TET family transcripts. Question marks to the left of the vertical dashed red line denote that technical variation cannot be completely excluded at this stage.

\section{Conclusion}

In conclusion, this is the first comprehensive analysis of methylation patterns at maternally- and paternallytransmitted imprinted gene associated DMRs during early embryo development in cattle. In contrast to the murine model, our evidence suggests that bovine germlineacquired DNA methylation imprints may be susceptible to instability at the blastocyst stage and are subsequently stabilized during a period involving notable increases in the transcription of genes involved in the regulation of DNA methylation. However, variation in methylation in bovine blastocysts due to technical issues associated with limited amounts of DNA cannot be fully ruled out. Single nucleotide polymorphism analysis (SNP) to identify the ratio of maternal and paternal alleles, and therefore eliminate/confirm amplification bias, would be the most definitive approach to determine whether blastocyst methylation variability is biological or technical. Unfortunately this information was not available for this investigation, but it should be considered in future studies investigating imprinted gene methylation in samples with limited numbers of cells. Finally, our studies highlight the usefulness of larger mammalian species as models for investigating epigenetic regulation during embryo development.

\section{Availability of supporting data}

All supporting data are included as additional files. 


\section{Additional files}

Additional file 1: Table S2. Bisulfite PCR pyrosequencing primers used in this study.

Additional file 2: Figure S1. Verification of the bovine $\mathrm{H} 19$ differentially methylated region. To confirm the methylation status of the H19 DMR included in this investigation it was analysed using three techniques. Combined Bisulfite Restriction Analysis (A) and bisulfite sequencing show that this DMR is hypomethylated in the oocyte and hemi-methylated in liver. Pyrosequencing analysis of the same region confirmed these observations in oocytes and liver and also illustrated that H19 is hypermethylated in sperm DNA.

Additional file 3: Table S1. Individual methylation values for imprinted gene DMRs during bovine pre-implantation embryo development.

Additional file 4: Figure S2A-B. DNA methylation analysis using limited starting amounts of genomic DNA as input for bisulfite conversions.

Additional file 5: Figure S4. DNMT3L mRNA expression during bovine embryonic development.

Additional file 6: Figure S3. D7 individual CpG methylation analysis.

\section{Competing interests}

The authors declare that they have no competing interests.

\section{Authors' contributions}

AOD \& TF conceived and designed the study and collected samples. AOD and DM drafted the manuscript. AOD carried out all DNA methylation pyrosequencing analysis. DM \& AOD performed statistical analysis on DNA methylation results. LOS performed protein expression experiments. MB generated and provided Day 25 embryos. SM provided RNAseq data. NF assisted with sample collection and RNAseq analysis. All authors approved and/or read the final manuscript.

\section{Acknowledgements}

This work was funded by SFI grant number 07/SRC/B1156. The opinions, findings, and conclusions expressed in this study are those of the authors and do not necessarily reflect the views of the Science Foundation Ireland. Thanks to Mr. Pat Duffy, Mrs. Mary Wade, UCD Lyons Research Farm, and Dr. Dimitris Rizos, Departamento de Reproducción Animal, Instituto Nacional de Investigación y Tecnología Agraria y Alimentaria (INIA), Madrid, Spain for assistance with sample collection. Acknowledgments to Dr. Colum Walsh's laboratory,Transcriptional Regulation and Epigenetics Research Group at the Centre for Molecular Biosciences, University of Ulster Coleraine, were pyrosequencing of samples was carried out.

\section{Author details}

${ }^{1}$ School of Agriculture and Food Science, University College Dublin, Belfield, Dublin, Ireland. ${ }^{2}$ School of Medicine and Medical Sciences, University College Dublin, Belfield, Dublin 4, Ireland. ${ }^{3}$ College of Agriculture, Health and Natural Resources, Animal Science, University of Connecticut, Connecticut, USA.

Received: 22 May 2014 Accepted: 12 February 2015

Published online: 10 March 2015

\section{References}

1. Preece MA, Moore GE. Genomic imprinting, uniparental disomy and foetal growth. Trends Endocrinol Metab. 2000;11(7):270-5.

2. Fowden AL, Sibley C, Reik W, Constancia M. Imprinted genes, placental development and fetal growth. Horm Res. 2006;65 Suppl 3:50-8.

3. Smith FM, Garfield AS, Ward A. Regulation of growth and metabolism by imprinted genes. Cytogenet Genome Res. 2006;113(1-4):279-91.

4. Davies W, Isles A, Smith R, Karunadasa D, Burrmann D, Humby T, et al. Xlr3b is a new imprinted candidate for $X$-linked parent-of-origin effects on cognitive function in mice. Nat Genet. 2005;37(6):625-9.

5. Reik W, Walter J. Genomic imprinting: parental influence on the genome Nat Rev Genet. 2001;2(1):21-32

6. Delaval K, Feil R. Epigenetic regulation of mammalian genomic imprinting. Curr Opin Genet Dev. 2004;14(2):188-95.
7. Davis TL, Yang GJ, McCarrey JR, Bartolomei MS. The H19 methylation imprint is erased and re-established differentially on the parental alleles during male germ cell development. Hum Mol Genet. 2000;9(19):2885-94.

8. Li JY, Lees-Murdock DJ, Xu GL, Walsh CP. Timing of establishment of paternal methylation imprints in the mouse. Genomics. 2004;84(6):952-60.

9. Hiura H, Obata $Y$, Komiyama J, Shirai M, Kono T. Oocyte growth-dependent progression of maternal imprinting in mice. Genes Cells. 2006;11(4):353-61.

10. Lucifero D, Mann MR, Bartolomei MS, Trasler JM. Gene-specific timing and epigenetic memory in oocyte imprinting. Hum Mol Genet. 2004;13(8):839-49.

11. O'Doherty AM, O'Shea LC, Fair T. Bovine DNA methylation imprints are established in an oocyte size-specific manner, which are coordinated with the expression of the DNMT3 family proteins. Biol Reprod. 2012;86(3):67

12. Dean W, Santos F, Stojkovic M, Zakhartchenko V, Walter J, Wolf E, et al. Conservation of methylation reprogramming in mammalian development: aberrant reprogramming in cloned embryos. Proc Natl Acad Sci U S A. 2001;98(24):13734-8.

13. Yang X, Smith SL, Tian XC, Lewin HA, Renard JP, Wakayama T. Nuclear reprogramming of cloned embryos and its implications for therapeutic cloning. Nat Genet. 2007;39(3):295-302.

14. Mayer W, Niveleau A, Walter J, Fundele R, Haaf T. Demethylation of the zygotic paternal genome. Nature. 2000;403(6769):501-2.

15. Oswald J, Engemann S, Lane N, Mayer W, Olek A, Fundele R, et al. Active demethylation of the paternal genome in the mouse zygote. Curr Biol. 2000;10(8):475-8

16. Reik W, Dean W, Walter J. Epigenetic reprogramming in mammalian development. Science. 2001:293(5532):1089-93.

17. Olek A, Walter J. The pre-implantation ontogeny of the $\mathrm{H} 19$ methylation imprint. Nat Genet. 1997;17(3):275-6.

18. Tremblay KD, Duran KL, Bartolomei MS. A 5' 2-kilobase-pair region of the imprinted mouse $\mathrm{H} 19$ gene exhibits exclusive paternal methylation throughout development. Mol Cell Biol. 1997;17(8):4322-9.

19. Imamura T, Kerjean A, Heams T, Kupiec JJ, Thenevin C, Paldi A. Dynamic CpG and non-CpG methylation of the Peg1/Mest gene in the mouse oocyte and preimplantation embryo. J Biol Chem. 2005:280(20):20171-5.

20. Smallwood SA, Tomizawa S, Krueger F, Ruf N, Carli N, Segonds-Pichon A, et al. Dynamic CpG island methylation landscape in oocytes and preimplantation embryos. Nat Genet. 2011;43(8):811-4.

21. Smith ZD, Chan MM, Mikkelsen TS, Gu H, Gnirke A, Regev A, et al. A unique regulatory phase of DNA methylation in the early mammalian embryo. Nature. 2012;484(7394):339-44.

22. Niemann H, Carnwath JW, Herrmann D, Wieczorek G, Lemme E, Lucas-Hahn $A$, et al. DNA methylation patterns reflect epigenetic reprogramming in bovine embryos. Cell Reprogram. 2010;12(1):33-42.

23. Gebert C, Wrenzycki C, Herrmann D, Groger D, Thiel J, Reinhardt R, et al. DNA methylation in the IGF2 intragenic DMR is re-established in a sex-specific manner in bovine blastocysts after somatic cloning. Genomics. 2009;94(1):63-9.

24. Tomizawa S, Kobayashi H, Watanabe T, Andrews S, Hata K, Kelsey G, et al. Dynamic stage-specific changes in imprinted differentially methylated regions during early mammalian development and prevalence of non-CpG methylation in oocytes. Development. 2011;138(5):811-20.

25. Smallwood SA, Kelsey G. De novo DNA methylation: a germ cell perspective. Trends Genet. 2012;28(1):33-42.

26. Lei $H$, Oh SP, Okano M, Juttermann R, Goss KA, Jaenisch $R$, et al. De novo DNA cytosine methyltransferase activities in mouse embryonic stem cells. Development. 1996;122(10):3195-205

27. Chen T, Li E. Establishment and maintenance of DNA methylation patterns in mammals. Curr Top Microbiol Immunol. 2006;301:179-201.

28. Bostick M, Kim JK, Esteve PO, Clark A, Pradhan S, Jacobsen SE. UHRF1 plays a role in maintaining DNA methylation in mammalian cells. Science. 2007;317(5845):1760-4

29. Okano M, Bell DW, Haber DA, Li E. DNA methyltransferases Dnmt3a and Dnmt3b are essential for de novo methylation and mammalian development. Cell. 1999;99(3):247-57.

30. Li E, Bestor $\mathrm{TH}$, Jaenisch R. Targeted mutation of the DNA methyltransferase gene results in embryonic lethality. Cell. 1992;69(6):915-26.

31. Bourc'his $D, X u G L$, Lin CS, Bollman B, Bestor TH. Dnmt3L and the establishment of maternal genomic imprints. Science. 2001;294(5551):2536-9.

32. Bourc'his D, Bestor TH. Meiotic catastrophe and retrotransposon reactivation in male germ cells lacking Dnmt3L. Nature. 2004;431(7004):96-9. 
33. Webster KE, O'Bryan MK, Fletcher S, Crewther PE, Aapola U, Craig J, et al. Meiotic and epigenetic defects in Dnmt3L-knockout mouse spermatogenesis. Proc Natl Acad Sci U S A. 2005;102(11):4068-73.

34. Hata K, Okano M, Lei H, Li E. Dnmt3L cooperates with the Dnmt3 family of de novo DNA methyltransferases to establish maternal imprints in mice. Development. 2002;129(8):1983-93.

35. Messerschmidt DM, de Vries W, Ito M, Solter D, Ferguson-Smith A, Knowles BB. Trim28 is required for epigenetic stability during mouse oocyte to embryo transition. Science. 2012;335(6075):1499-502.

36. Zuo X, Sheng J, Lau HT, McDonald CM, Andrade M, Cullen DE, et al. Zinc finger protein ZFP57 requires its co-factor to recruit DNA methyltransferases and maintains DNA methylation imprint in embryonic stem cells via its transcriptional repression domain. J Biol Chem. 2012;287(3):2107-18.

37. Wu H, Zhang Y. Reversing DNA methylation: mechanisms, genomics, and biological functions. Cell. 2014;156(1-2):45-68.

38. Edwards JL, Schrick FN, McCracken MD, van Amstel SR, Hopkins FM, Welborn MG, et al. Cloning adult farm animals: a review of the possibilities and problems associated with somatic cell nuclear transfer. Am J Reprod Immunol. 2003;50(2):113-23.

39. Young LE, Sinclair KD, Wilmut I. Large offspring syndrome in cattle and sheep. Rev Reprod. 1998;3(3):155-63.

40. Hill JR, Burghardt RC, Jones K, Long CR, Looney CR, Shin T, et al. Evidence for placental abnormality as the major cause of mortality in first-trimester somatic cell cloned bovine fetuses. Biol Reprod. 2000;63(6):1787-94.

41. Alexopoulos NI, Maddox-Hyttel P, Tveden-Nyborg P, D'Cruz NT, Tecirlioglu TR, Cooney MA, et al. Developmental disparity between in vitro-produced and somatic cell nuclear transfer bovine days 14 and 21 embryos: implications for embryonic loss. Reproduction. 2008;136(4):433-45.

42. Panarace M, Aguero Jl, Garrote M, Jauregui G, Segovia A, Cane L, et al. How healthy are clones and their progeny: 5 years of field experience. Theriogenology. 2007;67(1):142-51.

43. Kang YK, Koo DB, Park JS, Choi YH, Chung AS, Lee KK, et al. Aberrant methylation of donor genome in cloned bovine embryos. Nat Genet. 2001;28(2):173-7.

44. Rideout 3rd WM, Eggan K, Jaenisch R. Nuclear cloning and epigenetic reprogramming of the genome. Science. 2001;293(5532):1093-8.

45. Lucifero D, Suzuki J, Bordignon V, Martel J, Vigneault C, Therrien J, et al. Bovine SNRPN methylation imprint in oocytes and day 17 in vitro-produced and somatic cell nuclear transfer embryos. Biol Reprod. 2006;75(4):531-8.

46. Robbins KM, Chen Z, Wells KD, Rivera RM. Expression of KCNQ1OT1, CDKN1C, H19, and PLAGL1 and the methylation patterns at the KvDMR1 and H19/IGF2 imprinting control regions is conserved between human and bovine. J Biomed Sci. 2012;19:95.

47. Yamanaka K, Sakatani M, Kubota K, Balboula AZ, Sawai K, Takahashi M. Effects of downregulating DNA methyltransferase 1 transcript by RNA interference on DNA methylation status of the satellite I region and in vitro development of bovine somatic cell nuclear transfer embryos. J Reprod Dev. 2011;57(3):393-402.

48. Dobbs KB, Rodriguez M, Sudano MJ, Ortega MS, Hansen PJ. Dynamics of DNA methylation during early development of the preimplantation bovine embryo. PLoS One. 2013;8(6):e66230.

49. Hou J, Liu L, Lei T, Cui X, An X, Chen Y. Genomic DNA methylation patterns in bovine preimplantation embryos derived from in vitro fertilization. Sci China C Life Sci. 2007;50(1):56-61.

50. Beltman ME, Lonergan P, Diskin MG, Roche JF, Crowe MA. Effect of progesterone supplementation in the first week post conception on embryo survival in beef heifers. Theriogenology. 2009;71(7):1173-9.

51. Forde N, Beltman ME, Duffy GB, Duffy P, Mehta JP, O'Gaora P, et al. Changes in the endometrial transcriptome during the bovine estrous cycle: effect of low circulating progesterone and consequences for conceptus elongation. Biol Reprod. 2011;84(2):266-78.

52. Curchoe $\mathrm{CL}$, Zhang S, Yang L, Page R, Tian XC. Hypomethylation trends in the intergenic region of the imprinted IGF2 and H19 genes in cloned cattle. Anim Reprod Sci. 2009;116(3-4):213-25.

53. Levene H: Robust tests for equal variance. Contributions to Probability and Statistics: Essays in Honor of Harold Hotelling, I Olkin et al eds Stanford University Press 1960; 15(74):278-279

54. Mamo S, Mehta JP, McGettigan P, Fair T, Spencer TE, Bazer FW, et al. RNA sequencing reveals novel gene clusters in bovine conceptuses associated with maternal recognition of pregnancy and implantation. Biol Reprod. 2011;85(6):1143-51.
55. Gustafsson H, Ploen L. The morphology of 16 and 17 day old bovine blastocysts from virgin and repeat breeder heifers. Anat Histol Embryol. 1986;15(3):277-87.

56. Maddox-Hyttel P, Alexopoulos NI, Vajta G, Lewis I, Rogers P, Cann L, et al Immunohistochemical and ultrastructural characterization of the initial post-hatching development of bovine embryos. Reproduction. 2003;125(4):607-23.

57. Messerschmidt DM. Should I stay or should I go: Protection and maintenance of DNA methylation at imprinted genes. Epigenetics. 2012;7(9):969-75.

58. Gastwirth JL, Yulia R, Weiwen M. The Impact of Levene's Test of Equality of Variances on Statistical Theory and Practice. Statistical Sci. 2009;24(3):343-60.

59. Huntriss J, Woodfine K, Huddleston JE, Murrell A, Rutherford AJ, Elder K, et al. Quantitative analysis of DNA methylation of imprinted genes in single human blastocysts by pyrosequencing. Fertil Steril. 2011;95(8):2564-7. e2561-2568.

60. Market-Velker BA, Zhang L, Magri LS, Bonvissuto AC, Mann MR. Dual effects of superovulation: loss of maternal and paternal imprinted methylation in a dose-dependent manner. Hum Mol Genet. 2010;19(1):36-51.

61. Tada T, Tada M, Hilton K, Barton SC, Sado T, Takagi N, et al. Epigenotype switching of imprintable loci in embryonic germ cells. Dev Genes Evol. 1998;207(8):551-61.

62. Durcova-Hills G, Burgoyne P, McLaren A. Analysis of sex differences in EGC imprinting. Dev Biol. 2004;268(1):105-10.

63. Durcova-Hills G, Hajkova P, Sullivan S, Barton S, Surani MA, McLaren A. Influence of sex chromosome constitution on the genomic imprinting of germ cells. Proc Natl Acad Sci U S A. 2006;103(30):11184-8.

64. Douglas GC, VandeVoort CA, Kumar P, Chang TC, Golos TG. Trophoblast stem cells: models for investigating trophectoderm differentiation and placental development. Endocr Rev. 2009:30(3):228-40.

65. Reik W, Constancia M, Fowden A, Anderson N, Dean W, Ferguson-Smith A, et al. Regulation of supply and demand for maternal nutrients in mammals by imprinted genes. J Physiol. 2003;547(Pt 1):35-44.

66. Guillomot M, Taghouti G, Constant F, Degrelle S, Hue I, Chavatte-Palmer P, et al. Abnormal expression of the imprinted gene Phlda2 in cloned bovine placenta. Placenta. 2010;31(6):482-90.

67. Su JM, Yang B, Wang YS, Li YY, Xiong XR, Wang LJ, et al. Expression and methylation status of imprinted genes in placentas of deceased and live cloned transgenic calves. Theriogenology. 2011;75(7):1346-59.

68. Li X, Ito M, Zhou F, Youngson N, Zuo X, Leder P, et al. A maternal-zygotic effect gene, Zfp57, maintains both maternal and paternal imprints. Dev Cell. 2008;15(4):547-57.

69. Quenneville S, Verde G, Corsinotti A, Kapopoulou A, Jakobsson J, Offner S, et al. In embryonic stem cells, ZFP57/KAP1 recognize a methylated hexanucleotide to affect chromatin and DNA methylation of imprinting control regions. Mol Cell. 2011;44(3):361-72.

70. Lorthongpanich C, Cheow LF, Balu S, Quake SR, Knowles BB, Burkholder WF, et al. Single-cell DNA-methylation analysis reveals epigenetic chimerism in preimplantation embryos. Science. 2013;341(6150):1110-2.

\section{Submit your next manuscript to BioMed Central and take full advantage of:}

- Convenient online submission

- Thorough peer review

- No space constraints or color figure charges

- Immediate publication on acceptance

- Inclusion in PubMed, CAS, Scopus and Google Scholar

- Research which is freely available for redistribution 